BMJ Open

Diabetes

Research

\& Care

\section{Proinsulin to insulin ratio is associated with incident type 2 diabetes but not with vascular complications in the KORA F4/FF4 study}

To cite: Then C, Gar C, Thorand B, et al. Proinsulin to insulin ratio is associated with incident type 2 diabetes but not with vascular complications in the KORA F4/FF4 study. BMJ Open Diab Res Care 2020;8:e001425. doi:10.1136/ bmjdrc-2020-001425

$\checkmark$ Additional material is published online only. To view please visit the journal online (http://dx.doi.org/10.1136/ bmjdrc-2020-001425).

Received 31 March 2020 Revised 20 April 2020 Accepted 26 April 2020
Check for updates

C) Author(s) (or their employer(s)) 2020. Re-use permitted under CC BY-NC. No commercial re-use. See rights and permissions. Published by BMJ.

For numbered affiliations see end of article.

Correspondence to Dr Cornelia Then; cornelia.then@med.unimuenchen.de

\section{ABSTRACT}

Introduction We investigated the association of the proinsulin to insulin ratio (PIR) with prevalent and incident type 2 diabetes (T2D), components of the metabolic syndrome, and renal and cardiovascular outcomes in the population-based Cooperative Health Research in the Region of Augsburg (KORA) F4 study (2006-2008)/FF4 study (2013-2014).

Research design and methods The analyses included 1514 participants of the KORA F4 study at baseline and 1132 participants of the KORA FF4 study after a median follow-up time of 6.6 years. All-cause and cardiovascular mortality as well as cardiovascular events were analyzed after a median time of 9.1 and 8.6 years, respectively. The association of PIR with T2D, renal and cardiovascular characteristics and mortality were assessed using logistic regression models. Linear regression analyses were used to assess the association of PIR with components of the metabolic syndrome.

Results After adjustment for sex, age, body mass index (BMI), and physical activity, PIR was associated with prevalent (OR: 2.24; $95 \% \mathrm{Cl} 1.81$ to $2.77 ; \mathrm{p}<0.001$ ) and incident T2D (OR: 1.66; $95 \% \mathrm{Cl} 1.26$ to $2.17 ; \mathrm{p}<0.001$ ). PIR was associated with fasting glucose ( $\beta$ per SD: $0.11 \pm 0.02$; $p<0.001)$ and $\mathrm{HbA1c}(\beta: 0.21 \pm 0.02 ; p<0.001)$. However, PIR was not positively associated with other components of the metabolic syndrome and was even inversely associated with waist circumference $(\beta$ : $-0.22 \pm 0.03 ; p<0.001)$, BMI $(\beta$ $-0.11 \pm 0.03 ; p<0.001$ ) and homeostatic model assessment of insulin resistance $(\beta:-0.22 \pm 0.02 ; p<0.001)$. PIR was not significantly associated with the intima-media thickness (IMT), decline of kidney function, incident albuminuria, myocardial infarction, stroke, cardiovascular or all-cause mortality.

Conclusions In the KORA F4/FF4 cohort, PIR was positively associated with prevalent and incident T2D, but inversely associated with waist circumference, BMl and insulin resistance, suggesting that PIR might serve as a biomarker for T2D risk independently of the metabolic syndrome, but not for microvascular or macrovascular complications.

\section{INTRODUCTION}

Vascular complications and a roughly doubled risk for all-cause mortality pose a great burden to patients with type 2 diabetes (T2D). ${ }^{1}$

\section{Significance of this study}

What is already known about this subject?

- Elevated proinsulin may derive from compensatory hyperinsulinemia in insulin-resistant states and/or from inefficient proinsulin processing or premature proinsulin release, indicating an insulin secretion defect. To correct for compensatory hyperinsulinemia the proinsulin to insulin ratio instead of proinsulin was suggested. Whether the proinsulin to insulin ratio is independently associated with incident type 2 diabetes and cardiovascular complications is stil under debate.

What are the new findings?

- The proinsulin to insulin ratio was associated with an increased risk of incident type 2 diabetes in the Cooperative Health Research in the Region of Augsburg F4 study (2006-2008)/FF4 study (2013-2014).

- The proinsulin to insulin ratio was not positiveIy related to other components of the metabolic syndrome and was even inversely associated with waist circumference, body mass index and insulin resistance.

- The proinsulin to insulin ratio was not associated with the intima-media thickness as measure of prevalent subclinical atherosclerosis, nor with cardiovascular or all-cause mortality.

- The proinsulin to insulin ratio was not associated with decline of kidney function or incident albuminuria.

Gerald Reaven suggested that in T2D, insulin resistance causes compensatory hyperinsulinemia that will lead to the metabolic syndrome and finally results in cardiovascular disease. ${ }^{2}$ In line, the risk for cardiovascular disease has been shown to be doubled in insulin-resistant compared with insulin-sensitive individuals with pre-diabetes. ${ }^{3}$

Recently, the awareness for the heterogeneity of T2D has increased and efforts have been undertaken to define subgroups of T2D 


\section{Sigificance of this study}

How might these results change the focus of research or clinical practice?

- An elevated proinsulin to insulin ratio is an independent risk factor for the development of type 2 diabetes. Due to the lacking or even inverse association with other components of the metabolic syndrome and anthropometric measures, the proinsulin to insulin ratio might be an interesting candidate marker for lean individuals at risk for type 2 diabetes. Future research should focus on the question whether the proinsulin to insulin ratio represents a prognostic marker to identify patients with diabetes at a comparably lower risk for diabetes-associated complications. that may differ in terms of pathophysiology, treatment requirements and prognosis. Up to now, T2D was mainly regarded as a consequence of obesity-induced insulin resistance as part of the metabolic syndrome. ${ }^{4}$ However, lean individuals constitute a substantial proportion of patients with T2D and the pathophysiology of T2D in this group is still under debate. ${ }^{5}$ A deeper knowledge on the underlying pathophysiology and outcomes of such subtypes would enable a more personalized treatment and surveillance of patients with T2D. A new concept put forward by Ahlqvist $e t$ al uses six variables (glutamate decarboxylase antibodies, age at diagnosis, body mass index (BMI), HbAlc and homeostatic model assessment 2 estimates of $\beta$-cell function and insulin resistance) to assign adult-onset T2D into five clusters. ${ }^{6}$ Among them, three clusters mainly include participants with a low BMI: cluster 1, referred to as severe autoimmune diabetes and characterized by positive glutamate decarboxylase antibodies (GAD) antibodies; cluster 2, referred to as severe insulin-deficient diabetes (SIDD); and cluster 5 , referred to as mild age-related diabetes. The second cluster (SIDD) is characterized by low insulin secretion rather than insulin resistance. ${ }^{6}$ This subtype, according to Gerald Reaven, might be less likely to develop cardiovascular complications. ${ }^{2}$

Before the manifestation of diabetes, insulin alone is not able to discern healthy insulin-sensitive individuals from persons with a defect in insulin secretion as in both phenotypes insulin secretion is low. Proinsulin may be a marker for a leaner diabetes risk phenotype. Under physiological conditions, virtually all proinsulin is cleaved at residues $32-33$ and $65-66$ to produce $\mathrm{C}$ peptide and insulin. Only a small amount of intact proinsulin is released into the circulation along with the 32-33 split proinsulin and the 65-66 split proinsulin. ${ }^{7}$ Hyperproinsulinemia indicates a pathological state that may arise from inefficient proinsulin processing within the $\beta$-cell secretory granula or the premature release of proinsulin. ${ }^{8}$

Because high proinsulin secretion also appears along with high insulin secretion in compensatory hyperinsulinemia, the proinsulin to insulin ratio (PIR) is used to differentiate disproportionally elevated proinsulin from compensatory hyperinsulinemia. Several studies have shown that a high PIR indicates disturbed insulin secretion. $^{9-11}$ PIR has been connected to a primary defect in insulin secretion already in healthy individuals ${ }^{12}$ and associates with T2D in a prospective manner. ${ }^{13-17}$ Hence, PIR appears to be suitable to detect insulin deficiency already before the onset of T2D.

Our hypothesis was that PIR is associated with prevalent and incident T2D, but not with other components of the metabolic syndrome, the intima-media thickness (IMT) as marker for prevalent subclinical atherosclerosis, ${ }^{18}$ or cardiovascular or renal events in the population-based Cooperative Health Research in the Region of Augsburg (KORA) F4 study (2006-2008)/ FF4 study (2013-2014).

\section{METHODS}

\section{Study participants and definition of variables}

The KORA F4 (2006-2008) and FF4 (2013-2014) cohort studies are follow-up examinations of the populationbased KORA S4 study (1999-2001). Recruitment and eligibility criteria for the KORA studies, study design, standardized sampling methods and data collection (medical history, medication, anthropometric and blood pressure measurements) have been described elsewhere. ${ }^{19} 20$ All participants gave written informed consent before taking part. Total proinsulin was measured in the first 1567 participants of the KORA F4 study. Participants with a diabetes type other than type 2 or unknown glucose tolerance status $(n=25)$ and participants with T2D treated with insulin $(n=28)$ were excluded from the analyses. Of the remaining 1514 participants, 66 died before the follow-up examination and 316 declined participation in the FF4 survey or could not be contacted. After exclusion of participants with prevalent T2D in the baseline examination $(n=91)$, the study sample in the longitudinal F4/FF4 examination comprised 1001 participants for the analysis of incident T2D. Participants with missing covariates for other outcomes were excluded from the respective analyses. The numbers of participants included in each analysis are given in the results tables and illustrated in online supplementary figure 1 . The median (first quartile; third quartile) follow-up time was $6.6(6.4 ; 6.8)$ years.

Criteria for a clinically diagnosed diabetes mellitus were a validated medical diagnosis or current self-reported use of glucose-lowering agents. After an overnight fasting period, all participants without clinically diagnosed diabetes underwent a standard $75 \mathrm{~g}$ oral glucose tolerance test. Newly diagnosed diabetes, impaired glucose tolerance (IGT), impaired fasting glucose (IFG), and normal glucose tolerance (NGT) were defined according to the 1999 WHO diagnostic criteria based on both fasting and postchallenge glucose values (T2D: $\geq 7.0 \mathrm{mmol} / \mathrm{L}$ fasting and/or $\geq 11.1 \mathrm{mmol} / \mathrm{L}$ 2-hour glucose; IFG: $\geq 6.1$ and $<7.0 \mathrm{mmol} / \mathrm{L}$ fasting glucose; IGT: $\geq 7.8$ and $<11.1 \mathrm{mmol} / \mathrm{L}$ 2-hour glucose). Pre-diabetes was defined as IFG and/or IGT. 
Metabolic syndrome was defined according to the International Diabetes Federation definition as presence of at least three of the following five criteria: (1) elevated waist circumference (waist circumference $\geq 94 \mathrm{~cm}$ in men and $\geq 80 \mathrm{~cm}$ in women); (2) fasting triglycerides $\geq 1.7 \mathrm{mmol} / \mathrm{L}$ and/or use of fibrates or nicotinic acid; (3) high-density lipoprotein (HDL) cholesterol $<1.0 \mathrm{mmol} / \mathrm{L}$ in men or $<1.3 \mathrm{mmol} / \mathrm{L}$ in women and/or use of fibrates or nicotinic acid; (4) fasting glucose $\geq 5.6 \mathrm{mmol} / \mathrm{L}$ and/or use of glucose-lowering medication; (5) elevated blood pressure (systolic blood pressure $\geq 130 \mathrm{~mm} \mathrm{Hg}$ and/or diastolic blood pressure $\geq 85 \mathrm{~mm} \mathrm{Hg}$ and/or use of antihypertensive medication, given that the participants were aware of being hypertensive).

Arterial hypertension was defined as a systolic blood pressure $\geq 140 \mathrm{~mm} \mathrm{Hg}$ and/or a diastolic blood pressure $\geq 90 \mathrm{~mm} \mathrm{Hg}$, and/or intake of antihypertensive medication, given that the participants were aware of being hypertensive.

Leisure time physical activity was assessed with two separate questions concerning leisure time sport activity in winter and in summer (cycling included). Possible answers were: (1) >2 hours, (2) 1-2 hours, (3) <1 hour, and (4) none per week. Participants who had a total score $<5$, obtained by summing the numbers (1)-(4) from the winter and summer questions, were classified as 'physically active'.

Total mortality and cardiovascular mortality (International Classification of Diseases Ninth Revision codes 390-459 and 798) were ascertained by regularly checking the vital status of the participants through the population registries. Death certificates were obtained from the local health authorities. Incident non-fatal myocardial infarction occurring until the age of 75 years was assessed by surveillance through the local myocardial infarction registry. Incident non-fatal myocardial infarction occurring in participants $>74$ years or residing outside the study area, as well as non-fatal stroke were assessed by postal follow-up questionnaires. Using data from participants' hospital records and their attending physicians, all selfreported incident stroke cases and myocardial infarction cases occurring outside the study area or in persons $>74$ years and the date of diagnosis were validated. Stroke and myocardial infarction were pooled to a combined end point with the only first event taken into account in case of several events. Participants with prevalent stroke $(n=34)$ or prevalent myocardial infarction $(n=41)$ or missing data on incident stroke and myocardial infarction $(n=84)$ were excluded from the analyses regarding the outcome of incident myocardial infarction or stroke. The follow-up time (median (first quartile; third quartile)) was 9.1 (8.8; 9.4) years for total and cardiovascular mortality and 8.6 (8.1; 9.0) years for incident stroke/myocardial infarction.

\section{Laboratory measurements}

Blood samples were collected after an overnight fast of at least 8 hours and were kept at room temperature until centrifugation. Plasma was separated immediately, serum after $30 \mathrm{~min}$. Plasma and serum samples were assayed immediately or stored at $-80^{\circ} \mathrm{C}$. Blood glucose levels were assessed using the hexokinase method (GLU Flex; Dade Behring, Marburg, Germany). HDL cholesterol was measured with enzymatic methods (CHOD-PAP; Dade Behring). Triglycerides were measured by an enzymatic color test (GPO-PAP method, TGL Flex; Dade Behring). Serum creatinine was determined with a modified Jaffe test (Krea Flex; Dade Behring). Insulin was measured by an electrochemiluminescence immunoassay on a Cobas e602 instrument (Roche Diagnostics, Mannheim, Germany). HbAlc was measured in hemolyzed whole blood using the cation-exchange high-performance liquid chromatographic, photometric VARIANT II TURBO HbA1c Kit-2.0 assay on a VARIANT II TURBO Hemoglobin Testing System (Bio-Rad Laboratories, Hercules, USA). Intact proinsulin (frozen EDTA plasma) was measured by ELISA (intact human proinsulin ELISA, Cat No EZHIPI-17K, Linco Research, St Charles, MO). Estimated glomerular filtration rate (eGFR) was calculated using the Chronic Kidney Disease Epidemiology Collaboration equation (2009) based on serum creatinine. ${ }^{21}$ Homeostatic model assessment of insulin resistance (HOMA-IR) was calculated as fasting insulin (in $\mathrm{pmol} / \mathrm{L}) \times$ fasting glucose $($ in $\mathrm{mmol} / \mathrm{L}) \div 135$ in all participants except those with antidiabetic treatment.

\section{Measurement of IMT}

Ultrasound measurement (Sonoline G, $10 \mathrm{MHz}$ transducer; Siemens Medical Solutions, Munich, Germany) of both common carotid arteries (CCA) was performed using a validated protocol ${ }^{22}$ as previously described. ${ }^{23}$ Optimal images of the right and left CCAs far wall were recorded on DVD videotapes. IMT measurements were performed off line over a length of $10 \mathrm{~mm}$ beginning at $0-5 \mathrm{~mm}$ of the dilatation of the distal CCA using an automated edge detection reading system (Prowin software, Medical Technologies International, USA). We used the average of the measurements of three frozen images from both the left and right CCAs to calculate artery thickness of the distal CCA ((mean left+mean right)/2). One certified reader measured all IMT scans. Reproducibility studies for intersonographer ( $\mathrm{n}=30$ IMT measurements) and inter-reader variability ( $\mathrm{n}=50 \mathrm{IMT}$ measurements) revealed coefficients of variations of $1.9 \%$ and $3.0 \%$ with Spearman correlation coefficients of $\geq 0.89$.

\section{Statistical analyses}

Characteristics of the study participants were compared between participants with NGT and with pre-diabetes or T2D, respectively, using t-tests in case of approximately normally distributed variables. Mann-Whitney U tests were performed for variables with skewed distributions. Binomial proportions were compared with $\chi^{2}$ tests. The associations of PIR with the outcomes of interest were assessed in logistic regression models in case of categorical dependent variables and in linear regression models in case of continuous dependent variables. Continuous variables were transformed to a Gaussian distribution by 
the probability integral transformation followed by an inverse transform sampling and were used as in calculations per $1 \mathrm{SD}$. In multivariable logistic and linear regression analyses, the associations of PIR with the respective dependent variables were adjusted for covariates in different models: model 1: age (continuous), sex and physical activity (active/inactive); model 2: model 1 plus BMI (continuous); model 3: model 2 plus arterial hypertension. Smoking status (never/former/current), alcohol consumption (no; moderate (men 0.1 to $<40 \mathrm{~g}$ / day and women 0.1 to $<20 \mathrm{~g} /$ day); high (men $\geq 40 \mathrm{~g} /$ day and women $\geq 20 \mathrm{~g} /$ day $/$ high) ), low-density lipoprotein, HDL and triglycerides were not found to be associated with PIR after adjustment for sex, age and BMI and were therefore not included in the models. Pre-existing cases at baseline were excluded from the longitudinal incidence analyses. The level of statistical significance was set at $5 \%$ (two sided). The calculations were performed using the statistical environment R, V.3.6.0.

\section{RESULTS}

\section{Study population characteristics}

Table 1 displays the baseline characteristics of the total study population and stratified by diabetes status. PIR was higher in participants with T2D $(\mathrm{p}<0.001)$. Baseline characteristics of participants who progressed to T2D during the follow-up time versus non-progressors are shown in online supplementary table 1. PIR was elevated in participants who developed incident T2D in comparison to non-progressors $(\mathrm{p}<0.001)$.

\section{Association of PIR with T2D and glycemic traits}

An increased PIR was associated with a higher T2D prevalence (OR per SD 2.24; 95\% CI 1.81 to 2.77), a higher T2D incidence (OR: 1.66; 95\% CI 1.26 to 2.17), and with incident pre-diabetes after adjustment for sex, age, BMI and physical activity (table 2).

Cross-sectionally, PIR was directly related to HbAlc and fasting glucose (table 3). Interestingly, PIR was inversely associated with HOMA-IR. This inverse association was present in normoglycemic, pre-diabetic and diabetic participants with the weakest association in pre-diabetic individuals (online supplementary table 2).

Proinsulin alone was strongly associated with prevalent (OR 4.15; 95\% CI 3.14 to 5.48) and incident T2D (OR 3.72; $95 \%$ CI 2.55 to 5.42) after adjustment for sex, age, BMI and physical activity.

\section{Association of PIR with components of the metabolic syndrome and BMI}

In linear regression analysis with the components of the metabolic syndrome (table 4), PIR was directly associated with elevated fasting glucose and inversely associated with an elevated waist circumference. In line, PIR was inversely associated with BMI after adjustment for sex, age and physical activity $(\beta:-0.11 \pm 0.03 ; \mathrm{p}<0.001)$. PIR was not associated with the other components of the metabolic syndrome (elevated blood pressure, elevated triglycerides, and reduced HDL cholesterol) after adjustment for sex, age and physical activity.

In contrast, proinsulin alone was strongly directly associated with all components of the metabolic syndrome (online supplementary table 3 ).

\section{Lack of an association of PIR with IMT, decline of renal} function, cardiovascular events, cardiovascular mortality and all-cause mortality

Cross-sectionally, PIR was not significantly associated with IMT after adjustment for sex, age, BMI, arterial hypertension and physical activity (online supplementary table 4 ). In the longitudinal analysis, PIR was not associated with the incidence of a urinary albumin to creatinine ratio $\geq 30 \mathrm{mg} / \mathrm{g}$ and of an eGFR $<60 \mathrm{~mL} / \mathrm{min} / 1.73 \mathrm{~m}^{2}$ (online supplementary table 5). Further, an increased PIR was not related to the combined cardiovascular end point comprising non-fatal and fatal myocardial infarctions and stroke, nor to cardiovascular or all-cause mortality (table 5).

The association of proinsulin alone with IMT (online supplementary table 4), decline of kidney function and incident albuminuria (online supplementary table 5), the combined cardiovascular end point, cardiovascular mortality and all-cause mortality (online supplementary table 6$)$ were stronger in the crude analyses $(p<0.001$ for each observation) compared with the associations of PIR with the respective parameters. However, significance of these associations disappeared after multivariable adjustment, except for all-cause mortality, which remained significantly associated with proinsulin (HR $1.35 ; 95 \%$ CI 1.07 to $1.70 ; \mathrm{p}=0.012$ ).

\section{DISCUSSION}

In the population-based KORA F4/FF4 cohort, we showed that the PIR is positively associated with prevalent and incident T2D, but not with other components of the metabolic syndrome. In cross-sectional analyses we observed an association of PIR with HbAlc, fasting glucose and T2D. A further recent cross-sectional study by Nakamura et al described an association of fasting proinsulin with fasting glucose and T2D that was stronger than the association of PIR and the proinsulin to $\mathrm{C}$ peptide ratio. ${ }^{24}$ We confirmed a stronger association of proinsulin alone compared with PIR with prevalent and incident T2D. Nonetheless, PIR was independently related to a higher risk for incident pre-diabetes and T2D in our study. These results are in line with previous studies describing an association of PIR with incident T2D. ${ }^{13-17}$ However, other studies found no association of PIR with incident diabetes. ${ }^{25-27}$ These divergent findings might be explained by the shorter follow-up time of 24 months in the Hoorn study ${ }^{25}$ and the lower incidence of T2D in the study of Wareham et al. ${ }^{26}$

Interestingly, PIR associated inversely with HOMA-IR and anthropometric measures (BMI and waist circumference) in our study cohort, which fits the hypothesis 


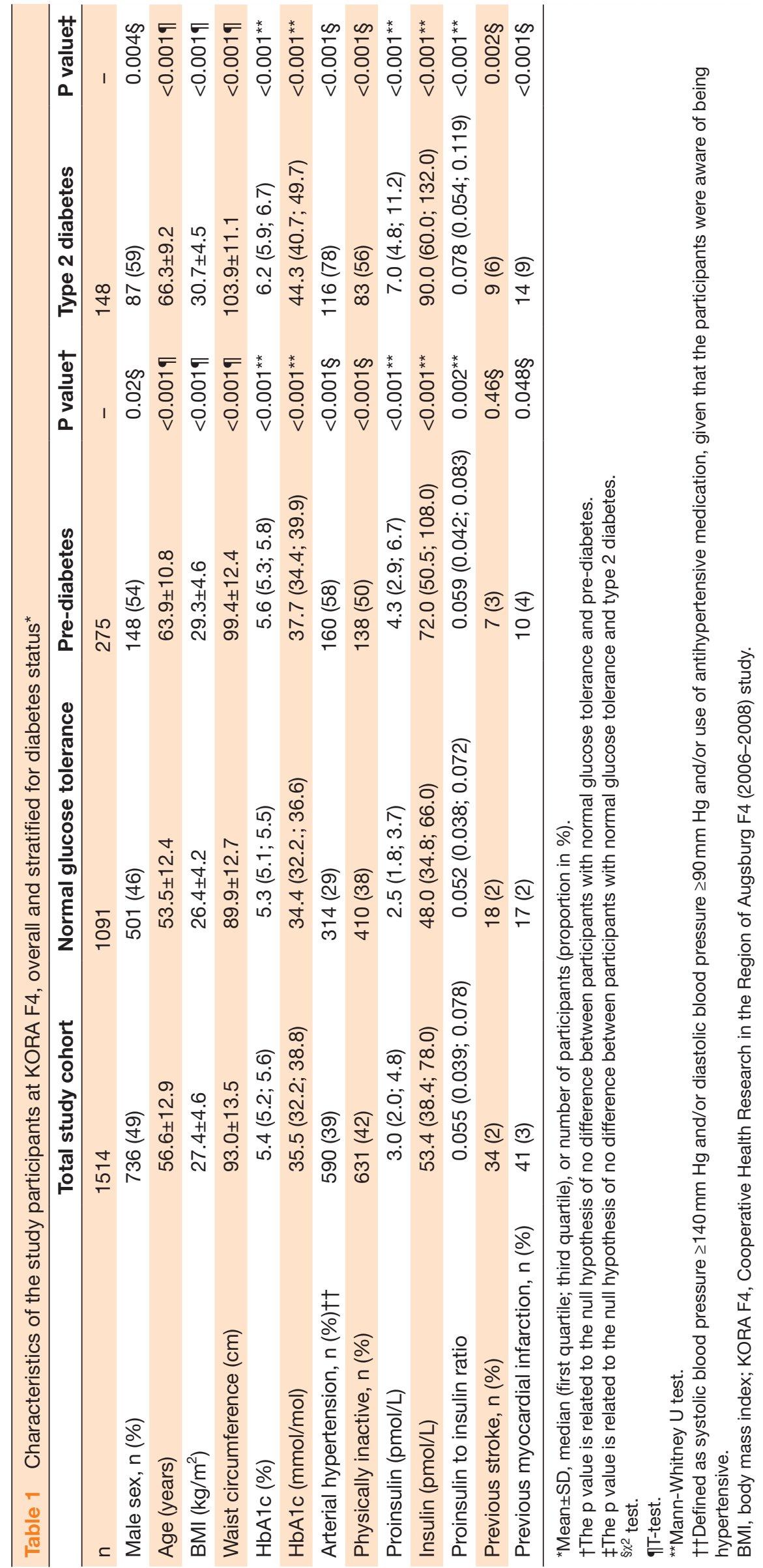


Table 2 ORs $(95 \% \mathrm{Cl})$ for prevalent pre-diabetes (vs normal glucose tolerance) and type 2 diabetes (vs no type 2 diabetes), as well as with incident pre-diabetes (vs non-progressors to pre-diabetes) and incident type 2 diabetes (vs non-progressors to type 2 diabetes) as dependent variables and proinsulin to insulin ratio as independent variable (per SD): results of logistic regression models

\begin{tabular}{|c|c|c|c|}
\hline $\begin{array}{l}\text { Prevalent pre-diabetes } \\
\text { (yes: } n=275 ; \text { no: } n=1091 \text { ) }\end{array}$ & $\begin{array}{l}\text { Prevalent type } 2 \text { diabetes } \\
\text { (yes: } n=148 ; n o: ~ n=1366 \text { ) }\end{array}$ & $\begin{array}{l}\text { Incident pre-diabetes } \\
\text { (yes: } n=135 ; \text { no: } n=677 \text { ) }\end{array}$ & $\begin{array}{l}\text { Incident type } 2 \text { diabetes } \\
\text { (yes: } n=79 ; n o: ~ n=922)\end{array}$ \\
\hline \multicolumn{4}{|l|}{ Without adjustment } \\
\hline $1.23(1.07 \text { to } 1.40)^{\star *}$ & $2.26(1.87 \text { to } 2.73)^{\star \star \star}$ & $1.24(1.03 \text { to } 1.50)^{*}$ & $1.58(1.24 \text { to } 2.01)^{\star \star \star}$ \\
\hline \multicolumn{4}{|c|}{ Adjustment for sex, age, BMI, physical activity (model 2) } \\
\hline $1.10(0.94$ to 1.29$)$ & $2.24(1.81 \text { to } 2.77)^{\star \star \star}$ & $1.27(1.03 \text { to } 1.57)^{\star}$ & $1.66(1.26 \text { to } 2.17)^{\star \star \star}$ \\
\hline
\end{tabular}

${ }^{*} \mathrm{p}<0.05 ;{ }^{* *} \mathrm{p}<0.01 ;{ }^{\star \star \star} \mathrm{p}<0.001$.

BMI, body mass index.

of an insulin-deficient T2D subtype that constitutes a low HOMA-IR (normal to high insulin sensitivity), but a high PIR (defect in insulin secretion). Our observation of an association of PIR with glucose metabolism that is independent of the metabolic syndrome is supported by a recent study showing increased proinsulin secretory ratios in non-obese participants with T2D compared with obese participants with T2D in response to a glucose-potentiated arginine test. ${ }^{28}$ In turn, high HOMA-IR, indicating insulin resistance (eg, in overweight or obesity), may initially be related to a low PIR in pre-diabetes or NGT, resulting from a compensatory hypersecretion of insulin, whereas proinsulin levels initially remain constant, leading to a decreased or normal PIR. ${ }^{172930}$ At a later stage, when $\beta$-cell failure and T2D become apparent, proinsulin levels will increase disproportionately, resulting in an elevated PIR. Hence, for insulin-resistant individuals, an elevated PIR may be found in manifest T2D, but not in pre-diabetes. In line, in our study, PIR was strongly elevated in diabetic participants, but was not associated with prevalent prediabetes in the regression analysis. Interestingly, however, PIR was associated with incident pre-diabetes, indicating that the underlying $\beta$-cell defect may be detectable in a very early stage before the progression to pre-diabetes, when insulin resistance-driven hyperinsulinemia might temporarily obscure the association. In line, the inverse

Table 3 Cross-sectional association estimates between proinsulin to insulin ratio and continuous glycemic traits: $\beta$ coefficients \pm SE from linear regression models are given per SD proinsulin to insulin ratio

\begin{tabular}{|c|c|c|}
\hline HbA1c & Fasting glucose & HOMA-IR \\
\hline $\begin{array}{l}\text { n (without/with } \\
\text { diabetes) }\end{array}$ & $\begin{array}{l}\mathrm{n} \text { (without/with } \\
\text { diabetes) }\end{array}$ & $\begin{array}{l}\mathrm{n} \text { (without/with } \\
\text { diabetes) }\end{array}$ \\
\hline $1366 / 148$ & $1366 / 148$ & $1366 / 82$ \\
\hline \multicolumn{3}{|c|}{ Without adjustment } \\
\hline $0.29 \pm 0.02^{\star \star \star}$ & $0.18 \pm 0.02^{\star \star \star}$ & $-0.12 \pm 0.03^{\star \star \star}$ \\
\hline \multicolumn{3}{|c|}{ Adjustment for sex, age, BMI, physical activity (model 2 ) } \\
\hline $0.21 \pm 0.02^{\star \star \star}$ & $0.11 \pm 0.02^{\star \star *}$ & $-0.22 \pm 0.02^{\star \star \star}$ \\
\hline
\end{tabular}

${ }^{\star * *} \mathrm{p}<0.001$

BMI, body mass index; HOMA-IR, homeostatic model assessment of insulin resistance. association between PIR and HOMA-IR was present in all glucose tolerance groups, but was lowest in participants with pre-diabetes, constituting the group with the highest proportion of primarily insulin-resistant participants with high insulin levels and preserved $\beta$-cell function with relatively low proinsulin levels. In contrast to our results, two recent cross-sectional studies found a positive association of PIR with HOMA-IR in diabetic participants ${ }^{31}$ and in obese Egyptians. ${ }^{32}$ However, these results were not corrected for possible confounders.

Apart from the direct association with elevated fasting glucose and the inverse association with an elevated waist circumference, PIR was not related to the other components of the metabolic syndrome, namely elevated triglycerides, reduced HDL cholesterol and elevated

Table 4 Cross-sectional association estimates between proinsulin to insulin ratio and components of the metabolic syndrome adjusted for sex, age and physical activity (model 1): $\beta$ coefficients \pm SE from linear regression models are given per SD

\begin{tabular}{|c|c|c|}
\hline & Adjusted $\beta \pm S E$ & P value \\
\hline $\begin{array}{l}\text { Elevated waist circumference* } \\
\text { (yes: } n=1011 ; \text { no: } n=503 \text { ) }\end{array}$ & $-0.22 \pm 0.03$ & $<0.001$ \\
\hline $\begin{array}{l}\text { Elevated triglycerides } † \\
\text { (yes: } n=371 ; \text { no: } n=1143 \text { ) }\end{array}$ & $0.08 \pm 0.08$ & 0.21 \\
\hline $\begin{array}{l}\text { Reduced HDL cholesterol } \neq \\
\text { (yes: } n=276 ; \text { no: } n=1238 \text { ) }\end{array}$ & $-0.08 \pm 0.07$ & 0.23 \\
\hline $\begin{array}{l}\text { Elevated fasting glucose } \\
\text { (yes: } n=463 ; \text { no: } n=1051 \text { ) }\end{array}$ & $0.30 \pm 0.06$ & $<0.001$ \\
\hline $\begin{array}{l}\text { Elevated blood pressure } \\
\text { (yes: } n=740 ; \text { no: } n=774 \text { ) }\end{array}$ & $0.03 \pm 0.06$ & 0.62 \\
\hline
\end{tabular}

*Defined as $\geq 80 \mathrm{~cm}$ in women and $\geq 94 \mathrm{~cm}$ in men. †Defined as $\geq 1.7 \mathrm{mmol} / \mathrm{L}$ and/or intake of fibrates or nicotinic acid. $\neq$ Defined as $<1.0 \mathrm{mmol} / \mathrm{L}$ in men and $<1.3 \mathrm{mmol} / \mathrm{L}$ in women and/ or intake of fibrates or nicotinic acid.

§Ddefined as $\geq 5.6 \mathrm{mmol} / \mathrm{L}$ and $/$ or intake of antidiabetic medication.

qDefined as systolic blood pressure $\geq 130 \mathrm{~mm} \mathrm{Hg}$ and/or diastolic blood pressure $\geq 85 \mathrm{~mm} \mathrm{Hg}$ and/or use of antihypertensive medication, given that the participants were aware of being hypertensive.

HDL, high-density lipoprotein. 
Table 5 HRs $(95 \% \mathrm{Cl})$ for overall mortality, cardiovascular mortality, non-fatal and fatal stroke, and non-fatal myocardial infarction or coronary death in dependence on proinsulin to insulin ratio (per SD)

\begin{tabular}{|c|c|c|c|}
\hline & All-cause mortality & Cardiovascular mortality & $\begin{array}{l}\text { Non-fatal or fatal stroke, myocardial } \\
\text { infarction, or coronary death }\end{array}$ \\
\hline n (non-cases)† & 1391 & 1459 & 1262 \\
\hline n (cases) $\ddagger$ & 123 & 55 & 93 \\
\hline \multicolumn{4}{|l|}{ Without adjustment } \\
\hline Total study cohort & $1.57(1.31 \text { to } 1.88)^{\star \star \star}$ & $1.74(1.33 \text { to } 2.27)^{\star \star \star}$ & $1.33(1.09 \text { to } 1.63)^{\star \star}$ \\
\hline \multicolumn{4}{|c|}{ Adjustment for sex, age, BMI, arterial hypertension, physical activity (model 3) } \\
\hline Total study cohort & 1.16 (0.96 to 1.42$)$ & $1.22(0.90$ to 1.64$)$ & $1.01(0.81$ to 1.26$)$ \\
\hline
\end{tabular}

${ }^{\star *} \mathrm{p}<0.01 ;{ }^{* * *} \mathrm{p}<0.001$.

†Number of participants without events.

$\ddagger$ Number of events.

BMI, body mass index.

blood pressure, which is in line with a study by Pivatto et al showing that proinsulin and insulin alone, but not PIR, were associated with the metabolic syndrome. ${ }^{33}$ In sum, these data indicate that the diabetes risk phenotype with an increased PIR is not primarily characterized by obesity, the metabolic syndrome, or insulin resistance.

Despite the increased risk of prevalent and incident T2D, PIR was not associated with IMT, incident albuminuria $\geq 30 \mathrm{mg} / \mathrm{g}$ creatinine, decline of kidney function below an eGFR of $60 \mathrm{~mL} / \mathrm{min} / 1.73 \mathrm{~m}^{2}$ and cardiovascular events and mortality even without adjustment for glucose tolerance status. This is in line with the literature on PIR and diabetic complications. ${ }^{345}$ It has to be noted that several studies found an association between proinsulin itself and cardiovascular complications. ${ }^{36-39}$ However, as outlined above, only PIR is corrected for an insulin resistance-driven hyperinsulinemia, whereas proinsulin alone will increase with increasing HOMA-IR. ${ }^{40}$ Thus, proinsulin is associated with insulin resistance, ${ }^{41}$ which may partly explain the association of proinsulin with cardiovascular events and mortality, ${ }^{42}$ since a high HOMA-IR has been shown to predict cardiovascular disease. ${ }^{43}$ Consequently, proinsulin alone may be associated with cardiovascular disease, but only PIR is suitable to detect a more insulin-sensitive but insulinopenic subtype of T2D risk, which possibly does not confer as strongly an increased risk for cardiovascular complications as the insulin-resistant T2D subtype. In our study, proinsulin alone was associated with all-cause mortality after multivariable adjustment, whereas the associations with IMT, the combined cardiovascular end point and cardiovascular mortality, which were highly significant in the crude analyses, lost significance after multivariable adjustment, supporting the view that proinsulin is not an independent cardiovascular risk factor in the KORA F4 cohort.

In a recent cross-sectional study, PIR was higher in participants with diabetic nephropathy compared with diabetic participants without nephropathy. ${ }^{31}$ However, long-standing T2D may provoke higher PIR irrespective of the underlying pathophysiology (insulin deficient vs insulin resistant), and a higher PIR in that study does not necessarily point to a more insulin-sensitive phenotype anymore. In insulin-resistant individuals with overt T2D, PIR might mainly indicate severity of dysglycemia, which probably is connected to nephropathy, and the study did not consider these possible confounders.

\section{Strengths and limitations}

The findings of our study are based on a large and well-characterized prospective study. Glucose tolerance status was determined by oral glucose tolerance test at baseline and follow-up visits. However, the KORA study included nearly exclusively Caucasians. Hence, our results may not apply to other ethnic groups. We used HOMA-IR instead of the gold standard methods (ie, hyperinsulinemic-euglycemic clamp) to measure insulin resistance. However, HOMA-IR is a widely used marker and can be considered as a reliable index for insulin resistance for clinical research purposes. ${ }^{44}$ The follow-up time for mortality and cardiovascular events was about 9 years. With a mean age of 56 years at baseline, cardiovascular events might occur at a higher age and therefore a longer follow-up time might be necessary. In sum, 123 deaths (about $8 \%$ of the cohort) and 93 first cardiovascular events were reported in this study. We cannot exclude that, with a longer follow-up time, we would have detected further events, which might have altered some of our results.

\section{CONCLUSION}

In conclusion, our results support the notion that PIR is elevated in a T2D risk subphenotype that is characterized by lower BMI and higher insulin sensitivity and that does not confer a higher rate of renal or cardiovascular events. Future studies focusing on lean individuals at high risk for T2D should further examine the value of PIR as prospective biomarker for incident pre-diabetes, T2D and secondary complications.

Author affiliations

${ }^{1}$ Medizinische Klinik und Poliklinik IV, LMU Klinikum der Universität München, Munich, Germany 
${ }^{2}$ Clinical Cooperation Group Diabetes, Ludwig-Maximilians-Universität München and Helmholtz Zentrum München, Munich, Germany

${ }^{3}$ Institute of Epidemiology, Helmholtz Zentrum München, Neuherberg, Germany ${ }^{4}$ Deutsches Zentrum für Diabetesforschung (DZD), German Center for Diabetes Research, München-Neuherberg, Germany

${ }^{5}$ Department of Mathematics, Freie Waldorfschule Augsburg, Augsburg, Germany ${ }^{6}$ Chair of Epidemiology at UNIKA-T Augsburg, Ludwig-Maximilians-Universität München, Munich, Germany

${ }^{7}$ KORA Study Centre, University Hospital Augsburg, Augsburg, Germany ${ }^{8}$ Institute of Epidemiology and Medical Biometry, Ulm University, Ulm, Germany ${ }^{9}$ Technische Universität München, Deutsches Herzzentrum München, München, Germany

${ }^{10}$ German Diabetes Center, Institute of Biometrics and Epidemiology, Leibniz Institute at Heinrich Heine University Düsseldorf, Düsseldorf, Germany

Acknowledgements We gratefully acknowledge the contribution of all field staff members conducting the KORA F4 study and thank all study participants.

Contributors Conception and design of the study: $\mathrm{BT}, \mathrm{CM}, \mathrm{CH}, \mathrm{MH}, \mathrm{AP}, \mathrm{WK}, \mathrm{WR}$, JS. Collection of data: BT, CT, CM, CH, MH, AP, WK, WR, AL, JS. Data analysis, interpretation of results, writing of the manuscript: CT, CG, HT, BT, CH, AL, JS. All authors revised the manuscript critically for important intellectual content and approved the final version.

Funding The KORA study was initiated and financed by the Helmholtz Zentrum München-German Research Center for Environmental Health, which is funded by the German Federal Ministry of Education and Research (BMBF) and by the State of Bavaria. The study was supported by a research grant from the Virtual Diabetes Institute (Helmholtz Zentrum München) and the Clinical Cooperation Group Diabetes, Ludwig-Maximilians-University München and Helmholtz Zentrum München, and by the German Diabetes Center. The German Diabetes Center was supported by the Federal Ministry of Health (Berlin, Germany) and the Ministry of Culture and Science of the state North Rhine Westphalia (Düsseldorf, Germany). Further support was obtained from the Deutsche Diabetes Gesellschaft (DDG). The KORA F4 study was partly funded by a grant from the German Research Foundation (DFG) (RA-45913/3-1).

Competing interests None declared.

Patient consent for publication Not required.

Ethics approval The study was approved by the Ethics Committees of the Bavarian Medical Association (approval number 06068) in adherence to the Declaration of Helsinki.

Provenance and peer review Not commissioned; externally peer reviewed.

Data availability statement Data are available upon reasonable request from the corresponding author.

Open access This is an open access article distributed in accordance with the Creative Commons Attribution Non Commercial (CC BY-NC 4.0) license, which permits others to distribute, remix, adapt, build upon this work non-commercially, and license their derivative works on different terms, provided the original work is properly cited, appropriate credit is given, any changes made indicated, and the use is non-commercial. See: http://creativecommons.org/licenses/by-nc/4.0/.

ORCID iDs

Cornelia Then http://orcid.org/0000-0001-5180-1973

Barbara Thorand http://orcid.org/0000-0002-8416-6440

\section{REFERENCES}

1 Huang D, Refaat M, Mohammedi K, et al. Macrovascular complications in patients with diabetes and prediabetes. Biomed Res Int 2017;2017:7839101.

2 Reaven GM. Insulin resistance, the insulin resistance syndrome, and cardiovascular disease. Panminerva Med 2005;47:201-10.

3 Salazar MR, Carbajal HA, Espeche WG, et al. Insulin resistance: the linchpin between prediabetes and cardiovascular disease. Diab Vasc Dis Res 2016;13:157-63.

4 Zaccardi F, Webb DR, Yates T, et al. Pathophysiology of type 1 and type 2 diabetes mellitus: a 90-year perspective. Postgrad Med $J$ 2016:92:63-9.

5 Taylor R, Holman RR. Normal weight individuals who develop type 2 diabetes: the personal fat threshold. Clin Sci 2015;128:405-10.

6 Ahlqvist E, Storm P, Käräämäki A, et al. Novel subgroups of adult-onset diabetes and their association with outcomes: a data- driven cluster analysis of six variables. Lancet Diabetes Endocrinol 2018:6:361-9.

7 Sizonenko S, Irminger JC, Buhler L, et al. Kinetics of proinsulin conversion in human islets. Diabetes 1993;42:933-6.

8 Mezza T, Ferraro PM, Sun VA, et al. Increased $\beta$-cell workload modulates Proinsulin-to-Insulin ratio in humans. Diabetes 2018;67:2389-96.

9 Festa A, Williams K, Hanley AJG, et al. Beta-Cell dysfunction in subjects with impaired glucose tolerance and early type 2 diabetes: comparison of surrogate markers with first-phase insulin secretion from an intravenous glucose tolerance test. Diabetes 2008;57:1638-44.

10 Røder ME, Porte D, Schwartz RS, et al. Disproportionately elevated proinsulin levels reflect the degree of impaired B cell secretory capacity in patients with noninsulin-dependent diabetes mellitus. $J$ Clin Endocrinol Metab 1998;83:604-8.

11 Lorenzo C, Hanley AJ, Rewers MJ, et al. Disproportionately elevated proinsulinemia is observed at modestly elevated glucose levels within the normoglycemic range. Acta Diabetol 2014;51:617-23.

12 Choi CS, Kim CH, Lee WJ, et al. Elevated plasma proinsulin/insulin ratio is a marker of reduced insulin secretory capacity in healthy young men. Horm Metab Res 1999;31:267-70.

13 Haffner SM, Gonzalez C, Mykkänen L, et al. Total immunoreactive proinsulin, immunoreactive insulin and specific insulin in relation to conversion to NIDDM: the Mexico City diabetes study. Diabetologia 1997;40:830-7.

14 Mykkänen L, Haffner SM, Kuusisto J, et al. Serum proinsulin levels are disproportionately increased in elderly prediabetic subjects. Diabetologia 1995;38:1176-82.

15 Schulze MB, Solomon CG, Rifai N, et al. Hyperproinsulinaemia and risk of type 2 diabetes mellitus in women. Diabet Med 2005;22:1178-84.

16 Kahn SE, Leonetti DL, Prigeon RL, et al. Proinsulin as a marker for the development of NIDDM in Japanese-American men. Diabetes 1995;44:173-9.

17 Pradhan AD, Manson JE, Meigs JB, et al. Insulin, proinsulin, proinsulin:insulin ratio, and the risk of developing type 2 diabetes mellitus in women. Am J Med 2003;114:438-44.

18 Simonetto C, Heier M, Rospleszcz S, et al. Risk for cardiovascular events responds nonlinearly to carotid intima-media thickness in the KORA F4 study. Atherosclerosis 2020;296:32-9.

19 Rathmann W, Strassburger K, Heier M, et al. Incidence of type 2 diabetes in the elderly German population and the effect of clinical and lifestyle risk factors: KORA S4/F4 cohort study. Diabet Med 2009;26:1212-9.

20 Huth C, von Toerne C, Schederecker F, et al. Protein markers and risk of type 2 diabetes and prediabetes: a targeted proteomics approach in the KORA F4/FF4 study. Eur J Epidemiol 2019;34:409-22.

21 Levey AS, Stevens LA, Schmid CH, et al. A new equation to estimate glomerular filtration rate. Ann Intern Med 2009;150:604-12.

22 Touboul P-J, Hennerici MG, Meairs S, et al. Mannheim intima-media thickness consensus. Cerebrovasc Dis 2004;18:346-9.

23 Kowall B, Ebert N, Then C, et al. Associations between blood glucose and carotid intima-media thickness disappear after adjustment for shared risk factors: the KorA F4 study. PLoS One 2012;7:e52590.

24 Nakamura A, Miyoshi H, Ukawa S, et al. Proinsulin is sensitive to reflect glucose intolerance. J Diabetes Investig 2020;11:75-9.

25 Nijpels G, Popp-Snijders C, Kostense PJ, et al. Fasting proinsulin and 2-h post-load glucose levels predict the conversion to NIDDM in subjects with impaired glucose tolerance: the Hoorn study. Diabetologia 1996;39:113-8.

26 Wareham NJ, Byrne CD, Williams R, et al. Fasting proinsulin concentrations predict the development of type 2 diabetes. Diabetes Care 1999;22:262-70.

27 Loopstra-Masters RC, Haffner SM, Lorenzo C, et al. Proinsulin-toC-peptide ratio versus proinsulin-to-insulin ratio in the prediction of incident diabetes: the insulin resistance atherosclerosis study (IRAS). Diabetologia 2011;54:3047-54.

28 Gudipaty L, Rosenfeld NK, Fuller CS, et al. Different $\beta$-cell secretory phenotype in non-obese compared to obese early type 2 diabetes. Diabetes Metab Res Rev 2020;4:e03295.

29 Vangipurapu J, Stančáková A, Kuulasmaa T, et al. Both fasting and glucose-stimulated proinsulin levels predict hyperglycemia and incident type 2 diabetes: a population-based study of 9,396 Finnish men. PLoS One 2015;10:e0124028.

30 Blicklé JF, Sapin R, Andrès E. Contribution of total and intact proinsulins to hyperinsulinism in subjects with obesity, impaired glucose tolerance or type 2 diabetes. Diabetes Metab 2000;26:274-80. 
31 El-Messallamy FAF, El-Ashmawy HM, El Shabrawy AM, et al. Proinsulin/insulin ratio as a predictor of insulin resistance in patients with diabetic nephropathy. Diabetes Metab Syndr 2019:13:2057-60.

32 El Shabrawy AM, Elbana KA, Abdelsalam NM. Proinsulin/insulin ratio as a predictor of insulin resistance and $B$-cell dysfunction in obese Egyptians ((insulin resistance \& B-cell dysfunction in obese Egyptians)). Diabetes Metab Syndr 2019;13:2094-6.

33 Pivatto I, Bustos $\mathrm{P}$, Amigo $\mathrm{H}$, et al. Association between proinsulin, insulin, proinsulin/insulin ratio, and insulin resistance status with the metabolic syndrome. Arq Bras Endocrinol Metabol 2007;51:1128-33.

34 Alssema M, Dekker JM, Nijpels G, et al. Proinsulin concentration is an independent predictor of all-cause and cardiovascular mortality: an 11-year follow-up of the Hoorn study. Diabetes Care 2005;28:860-5.

35 Yudkin JS, May M, Elwood P, et al. Concentrations of proinsulin like molecules predict coronary heart disease risk independently of insulin: prospective data from the Caerphilly study. Diabetologia 2002;45:327-36.

36 Zethelius B, Byberg L, Hales CN, et al. Proinsulin is an independent predictor of coronary heart disease: report from a 27 -year follow-up study. Circulation 2002;105:2153-8.
37 Lindahl B, Dinesen B, Eliasson M, et al. High proinsulin concentration precedes acute myocardial infarction in a nondiabetic population. Metabolism 1999;48:1197-202.

38 Lindahl B, Dinesen B, Eliasson M, et al. High proinsulin levels precede first-ever stroke in a nondiabetic population. Stroke 2000;31:2936-41.

39 Båvenholm P, Proudler A, Tornvall P, et al. Insulin, intact and split proinsulin, and coronary artery disease in young men. Circulation 1995;92:1422-9.

40 Pfützner $\mathrm{A}$, Kann $\mathrm{PH}$, Pfützner $\mathrm{AH}$, et al. Intact and total proinsulin: new aspects for diagnosis and treatment of type 2 diabetes mellitus and insulin resistance. Clin Lab 2004;50:567-73.

41 Pfützner A, Kunt T, Hohberg C, et al. Fasting intact proinsulin is a highly specific predictor of insulin resistance in type 2 diabetes. Diabetes Care 2004;27:682-7.

42 Hedblad B, Nilsson P, Engström G, et al. Insulin resistance in non-diabetic subjects is associated with increased incidence of myocardial infarction and death. Diabet Med 2002;19:470-5.

43 Zhang X, Li J, Zheng S, et al. Fasting insulin, insulin resistance, and risk of cardiovascular or all-cause mortality in non-diabetic adults: a meta-analysis. Biosci Rep 2017;37.

44 Gutch M, Kumar S, Razi SM, et al. Assessment of insulin sensitivity/ resistance. Indian J Endocrinol Metab 2015;19:160-4. 